\title{
ANALYSIS OF THE EFFECTIVENESS OF PUBLIC INTERNAL CONTROL SYSTEM: EXAMPLE OF STATE UNIVERSITIES
}

\author{
DOI: 10.17261/Pressacademia.2019.1093 \\ PAP-V.9-2019(40)-p.203-208
}

\section{Gokhan Ozer ${ }^{1}$, Abdullah Kursat Merter², Serkan Cinar ${ }^{3}$}

${ }^{1}$ Gebze Technical University, Faculty of Business Administration, Istanbul, Turkey gokozerhan@gmail.com, ORCID: 0000-0002-3255-998X

${ }^{2}$ Gebze Technical University, Faculty of Business Administration, Istanbul, Turkey, akmerter@gtu.edu.tr,ORCID: 0000-0001-6874-1890

${ }^{3}$ Gebze Technical University, Graduate School of Social Sciences, Istanbul, Turkey, serkan.cinar@hotmail.com_ORCID: 0000-0001-6195-4893

\section{To cite this document}

Ozer, G., Merter A.K., Cinar S., (2019). Analysis of the effectiveness of public internal control system: example of state universities. PressAcademia Procedia (PAP), V.9, p.203-208

Permemant link to this document: http://doi.org/10.17261/Pressacademia.2019.1093

Copyright: Published by PressAcademia and limited licenced re-use rights only.

\section{ABSTRACT}

Purpose- To determine the factors that affect the effectiveness of public internal control system, to propose a model that will reveal the effect of these factors on public internal control system and to test this model on public university employees.

Methodology- Research topics within the scope of the tasks for which the Internal Auditor at the state universities in Turkey and Strategy Development Department employees Likert scale questionnaire was administered. The data obtained from 176 state university employees who participated in the survey were tested with Smart PLS 3.0 package program.

Findings- According to the results of the survey, it has been concluded that senior management support to the public internal control system, effective public internal audit system, the competence of public employees and the use of information technologies in public internal control system have a statistically significant positive effect on the effectiveness of public internal control system.

Conclusion- In order to ensure the effectiveness of the public internal control system, it is recommended that the senior management support the work of the public internal control system, that the internal audit system in public institutions is enabled, that the competence of public employees is ensured, and that the information technologies of the public institutions are aligned with the internal control systems.

Keywords: Public, internal control, efficiency.

JEL Codes : M41, M42

\section{KAMU iç KONTROL SISTEMI ETKINLIĞi ANALIZi: DEVLET ÜNIVERSITELERi ÖRNEĞi}

\section{ÖZET}

Amaç- Kamu iç kontrol sistemi etkinliğinin sağlanmasına etki eden faktörleri belirlemek, bu faktörlerin kamu iç kontrol sistemine etkisini ortaya koyacak bir model önermek ve bu modeli devlet üniversiteleri çalışanları üzerinde test etmektir.

Methodoloji- Araştırma konusu kapsamında Türkiye'deki devlet üniversitelerinde görev yapan İç Denetçilere ve Strateji Geliştirme Dairesi Başkanlığı çalışanlarına yönelik olarak likert ölçekli anket uygulanmıştır. Ankete katılan 176 devlet üniversitesi çalışanından elde edilen veriler Smart PLS 3.0 paket programı ile test edilmiştir.

Bulgular- Anket sonuçlarına göre kamu iç kontrol sistemine üst yönetim desteği, etkin kamu iç denetim sistemi, kamu çalışanlarının yetkinliği ve kamu iç kontrol sisteminde bilgi teknolojileri kullanımının kamu iç kontrol sistemi etkinliğini istatistiksel olarak anlamlı bir biçimde pozitif etkilediği sonucuna varılmıştır.

Sonuç- Kamu iç kontrol sisteminin etkinliğinin sağlanabilmesi için üst yönetimin kamu iç kontrol sistemi çalışmalarını desteklemesi, kamu kurumlarında iç denetim sisteminin etkinleştirilmesi, kamu çalışanlarının yetkinliğinin sağlanması ve kamu kurumlarının sahip olduğu bilgi teknolojileri ile iç kontrol sistemlerinin uyumlaştırılması önerilmektedir.

Anahtar Kelimeler: Kamu, iç kontrol, etkinlik.

JEL Kodları: M41, M42 


\section{GiRiş}

Kamu kurumları varlıklarını sürdürebilmeleri için bir yandan kaynaklarını etkin, ekonomik ve verimli kullanmaları gerekmekte, diğer yandan iç ve dış paydaş beklentilerini bütçe disiplini çerçevesinde karşılayabilmeleri gerekmektedir. Kamu kurumları, bu çerçevede yönetim fonksiyonları olan planlama, organizasyon, koordinasyon, yönlendirme ve kontrol süreçlerini devamlı olarak iyileştirme yapmaya çalışılmakta ve bu yolla katma değer sağlamayı hedeflemektedirler. Yönetim fonksiyonları içerisinde Avrupa Birliği müktesebatına uygunluğun sağlanması için kamu yönetimimize dahil olan ve etkin bir feedback (geri besleme) mekanizmasının çalışabilmesi adına hayati öneme sahip olan kontrol fonksiyonun 5018 sayılı Kanundaki karşılı̆ı iç kontrol sistemi olarak ifade edilmektedir. Dünyada iç kontrol sisteminin önemi hem kamu sektöründe hem de özel sektöründe her geçen gün artmasına rağmen ülkemiz kamu kesimi açısından ele alındığında yaklaşık 15 yıllık uygulama sürecinde kamu iç kontrol sisteminden beklenilen etkinlik seviyesine ulaşılamadığı görülmektedir. Bu durumun bir sonucu olarak Orta Vadeli Mali Planda 32. faslın alt bileşeni olan Avrupa Birliği müktesebatına uygun, risk esaslı, etkin izleme fonksiyonu olan, kurumsallaşmış, etkin bir kamu iç kontrol sisteminin kurulması hedeflenmektedir. Bu araştırma ile kamu kurumlarında iç kontrol sistemi etkinliğine etki eden faktörler sorgulanacak olup Avrupa Birliği müktesebatına uygun, risk esaslı, etkin izleme fonksiyonu olan, kurumsallaşmış, etkin bir iç kontrol sisteminin sağlanması hedefine katkı sunulmaya çalışılacaktır.

\section{LITERATÜR ÖZETi}

\subsection{Kamu İç Kontrol Sistemi}

5018 Sayılı Kamu Mali Yönetimi ve Kontrol Kanununda kamu iç kontrol sistemi; "idarenin misyonuna, belirlenmiş politikalara ve yasal mevzuata uygun bir şekilde faaliyetlerin etkili, ekonomik ve verimli bir şekilde gerçekleştirilmesi, varlık ve kaynakların korunmasını, muhasebe bilgi sisteminin doğru ve tam olarak tutulmasını, malî bilgi ve yönetim bilgisinin zamanında ve güvenilir olarak üretilmesini gerçekleştirmek üzere idarece oluşturulan organizasyon, yöntem ve süreçle iç denetimi içine alan malî ve mali olmayan kontroller bütünü" olarak ifade edilmektedir. Bu tanımdan hareketler iç kontrol siteminin kamu yönetim sistemimizdeki amaçları yine aynı Kanunun 56 . Maddesinde şu şekilde sıralanmıştır.
$\checkmark \quad$ Kamu gelir, gider, varlık ve yükümlülüklerinin etkili, ekonomik ve verimli bir şekilde yönetilmesini,
$\checkmark \quad$ Kamu idarelerinin kanunlara ve diğer düzenlemelere uygun olarak faaliyet göstermesini,
$\checkmark \quad$ Her türlü malî karar ve işlemlerde usulsüzlük ve yolsuzluğun önlenmesini,
$\checkmark \quad$ Karar oluşturmak ve izlemek için düzenli, zamanında ve güvenilir rapor ve bilgi edinilmesini,
$\checkmark \quad$ Varlıkların kötüye kullanılması ve israfını önlemek ve kayıplara karşı korunmasını, sağlamaktır.

\subsection{Kamu İç Kontrol Sistemi Etkinliği}

İç kontrol, yöneticilerin kurumu harekete geçirmek ve amaçlarını süreklilik temelinde gerçekleştirmelerine yardımcı olmak üzere alt yapının bir parçası olarak oluşturulan bir yönetim kontrolüdür (Korkmaz, 2007). İç kontrol sistemi, yönetim için kullanımı tercihe bağıı ancak önemli bir yardımcı bir araç niteliğindedir. Bu nedenle iç kontrol sisteminin etkinliği her kurum için aynı seviyede değildir. Yılancı, (2006) göre iç kontrol sistemi, standartları olan, ulusal ve uluslararası birçok kurumda uygulanan bir sistem olmasına rağmen sistemin farklı zamanlarda farklı etkinlik seviyesinde olabilir. Bu durum iç kontrol sistemi etkinliği önemini ve sistemi etkileyen faktörlerin sorgulanması ihtiyacını ortaya çıkarmaktadır. İç kontrol sistemi etkinliğinin neden önemli konusunda yapılan bazı çalışmalarda; Vijayakumar ve Nagaraja'a (2012) göre kamu kuruluşları yönetim organlarını etkili bir iç kontrol sistemi ile yönetilmediklerinde önemli risklerle karşı karşıya kalabilirler ve bu nedenle etkin bir iç kontrol sistemi kurumları başarıya götürecek ve onların performansını arttıracak hayati bir faktördür. Lalic ve arkadaşlarına (2009) göre kurumlarda etkin olmayan iç kontrol sisteminin varlığı kurumların hedeflerine ulaşılmasında ciddi problemlere sebebiyet verebilir. Jokipii'e (2010) göre iç kontrol sistemi, bir kurumun süreçlerinin ilerleyişi hakkında ve hedeflerine ulaşılmasına yönelik ilerleme eksikliği hakkında bilgi sağlayarak kurumların başarısında önemli rol oynayabileceğinden kurumların iç kontrol sisteminin etkinliğinin sağlanması gerekmektedir. Iç̧ kontrol sisteminin etkinliğini etkileyen faktörlerin neler olduğuna ilişkin yapılan çalışmalarda ise; Root'a (1998) göre iç kontrol sistemi dinamik unsurlardan oluşmaktadır ve bu nedenle iç kontrol sistemi etkinliğine etki eden unsurlar genel olarak; kurumsal yönetim anlayışı, değer yaratma, riskler-fırsatlar, yasal düzenlemeler, kültürel gelişim, teknolojik gelişim ve etkin bir muhasebe sistemidir. Verovska'ya (2012) göre iç kontrol sisteminin etkinliği bir dengeye dayanır. Bu denge iç kontrol sisteminin maliyeti ile onun ilişkili olduğu riskler arasındaki dengedir. Aşırı iç kontrol faaliyetleri iç kontrolün maliyeti arttırır, verimliliğini azaltır bu nedenle iç kontrol uygulamalarında etkinliğin sağlanabilmesi için bu dengenin kurulması önemlidir. Girinüas (2009) kurumların iç kontrol sistemlerine etki eden temel faktörleri iç kontrol ortamına etki eden faktörlerin etkisi, iç kontrol sistemine veri girişi sağlayan sistemlerinin etkinliği, bilgi iletişim sistemlerinin etkinliği, etkin performans ölçüm sistemlerinin varlığı ve etkin bir geri bildirim sisteminin varlığı olarak açıklamıştır. Kumuthinidevi, (2016) özel bankaların iç kontrol sistemi etkinliğini etkileyen faktörler üzerine yaptığı çalışmada kontrol ortamı, risk değerlendirme, muhasebe sistemi, bilgi- iletişim sistemi ve öz değerlendirmenin sistemin etkinliğini etkileyen faktörler olduğunu ortaya koymuştur. Dormán ve arkadaşlarına (2013) göre iç kontrol sistemi, kurumun faaliyetleri ile entegre olduğunda, altyapısına yerleştiğinde ve kurumun ayrılmaz bir parçası olduğunda etkindir. Bunun sağlanması için yönetim desteği, etkin risk yönetimi, etkin izleme sistemi ve destekleyici iç denetim faaliyetlerinin olması gerektiğini belirtmiştir. Akyel'e (2010) göre iç kontrol sisteminin etkinliğini belirleyen faktörler; görev ve sorumlulukların etkin dağıtılması, mesleki yetkinlik ve etik bilinci ile denetim bulgularının önemsenmesidir. Literatür araştırması sonucunda genel olarak iç kontrol sisteminin etkinliğini etkileyen iç ve dış birçok faktör bulunmaktadır. Bu nedenle iç kontrol sistemi etkinliğine ilişkin genel bir modele literatürde rastlanılmamıştır. Araştırmamızda zaman ve maliyet kısıtı, daha önceki çalışmalar ve ülkemiz kamu sektörünün yapısal özellikleri dikkate alındığında kamu iç kontrol sistemi etkinliğinin sağlanmasında etki edebilecek faktörler olarak; kamu iç kontrol sistemine üst yönetim desteği, etkin kamu iç 
denetim sistemi, kamu çalışanlarının yetkinliği ve kamu iç kontrol sisteminde bilişim teknolojileri kullanımı faktörlerinin etkisi ortaya konulmaya çalışılacak olup bu kapsamda aşağıdaki hipotezler geliştirilmiştir.

H-1. Kamu iç kontrol sistemine üst yönetim desteği, kamu iç kontrol sistemi etkinliğini pozitif etkiler.

H-2. Etkin bir kamu iç denetim sistemi, kamu iç kontrol sistemi etkinliğini pozitif etkiler.

H-3. Kamu çalışanlarının yetkinliği, kamu iç kontrol sistemini etkinliğini pozitif etkiler.

H-4. Kamu iç kontrol sisteminde bilgi teknolojileri kullanımı, kamu iç kontrol sistemi etkinliğini pozitif yönde etkiler.

\section{ARAŞTIRMA METEDOLOLISI VE YÖNTEM}

\subsection{Araştırmanın Amacı, Ana kütlesi ve Örneklemi}

Bu çalışmanın amacı kamu iç kontrol sistemi etkinliğinin sağlanmasına etki eden faktörleri belirlemek, bu faktörlerin kamu iç kontrol sistemine etkisini ortaya koyacak bir model önermek ve bu modeli devlet üniversiteleri çalışanları üzerinde test etmektir. Araştırmamızın ana kütlesini, 5018 Sayılı Kanunun III/A Sayılı cetvelinde yer alan; devlet üniversiteleri oluşturmaktadır.

Araştırmada zaman ve maliyet kısıtı ve araştırma konusu farkındalığından dolayı örneklem alanı olarak Türkiye'deki devlet üniversitelerinin İç Denetim Birimleri/Başkanlıkları ile Strateji Daire Başkanlığında görev yapan çalışanlar olarak belirlenmiştir Devlet üniversitelerinin İç Denetim Birimleri/Başkanlıkları ile Strateji Geliştirme Başkanlıklarında görev yapan personele yüz yüze uygulanan ankete 48 iç denetçi, 128 strateji geliştirme personeli olmak üzere toplam 176 personel katılmıştır.

\subsection{Veri Toplama Araçları}

Araştırma için oluşturulan hipotezlerin test edilmesi amacıyla uluslararası literatürde geçerliliği ve güvenilirliği test edilmiş ölçekler araştırılmış ve araştırma konusu için uygun görülen ölçekler ingilizceden türkçeye çevrilerek çalışmaya dahil edilmiştir. Araştırma konusu ile ilgili olarak, demografik özellik ölçümü dışındaki bütün ölçümlerde değişkenleri değerlendirmede kolaylık olması için $5^{\prime}$ li likert tipi değerlendirme seçeneği oluşturulmuştur. Kamu iç kontrol sistemine üst yönetim desteği ölçeği için Cohen ve Sayag (2010) ile Alzeban ve Gwilliam (2014) çalışmasından, kamu iç denetim sistemi etkinliği ölçeği için Alzeban ve Gwilliam (2014) çalışmasından, kamu çalışanlarının yetkinliği ölçeği için Schwarzer ve Jerusalem (1995) çalışmasından, kamu iç kontrol sisteminde bilgi teknolojileri kullanımı ölçeği için Aunga ve Ilomo (2017) çalışmasından ve kamu iç kontrol sistemi etkinliği ölçeği için ise Aziz ve arkadaşlarının (2015) çalışmasından yararlanılmıştır.

\section{BULGULAR VE TARTIŞMA}

\subsection{Demografik Göstergeler}

Ankete katılanların yaş dağılımı, eğitim durumu ve kurumdaki görevlerine göre dağılımları aşağıdaki tablodaki gibidir.

Tablo 1: Katılımcıların Demografik Özelliklerine Dağılım Durumu

\begin{tabular}{|c|c|c|c|c|c|c|c|c|}
\hline Yaș & Frekans & $\underline{\text { Yüzde }}$ & Eğitim & Frekans & $\underline{\text { Yüzde }}$ & Kamu Görevi & Frekans & $\underline{\text { Yüzde }}$ \\
\hline$\overline{18-30}$ & $\overline{26}$ & $\overline{14,78}$ & Lise & 15 & 8,6 & $\overline{\text { Kamu İç Denetçisi }}$ & 50 & $\overline{28,41}$ \\
\hline $31-40$ & 61 & 34,65 & Önlisans & 8 & 4,5 & Daire Başkanı & 5 & 2,84 \\
\hline $41-50$ & 75 & 42,61 & Lisans & 104 & 59,1 & Şube Müdürü & 18 & 10,24 \\
\hline 51 ve üstü & 14 & 7,96 & Yüksek Lisans & 44 & 25 & Şef & 15 & 8,52 \\
\hline \multirow[t]{4}{*}{ Toplam } & 176 & 100 & Doktora & 5 & 2,8 & Mali Hizmetler Uzmanı & 15 & 8,52 \\
\hline & & & Toplam & 176 & 100 & Bilgisayar İşletmeni & 25 & 14,20 \\
\hline & & & & & & Diğer & 48 & 27,27 \\
\hline & & & & & & Toplam & 176 & 100 \\
\hline
\end{tabular}

\subsection{Güvenilirlik ve Geçerlilik Ölçümü}

Kamu iç kontrol sistemine üst yönetim desteği değişkeni "KiKSÜYD”, etkin kamu iç denetim sistemi "EKiDS", kamu çalışanları yetkinliği “KÇY", kamu iç kontrol sisteminde bilişim teknolojileri kullanımı "KiKSBTK", kamu iç kontrol sistemi etkinliği "KiKSE" olarak adlandırılmıştır. Güvenilirliğin ölçülmesi için kompozit ölçek güvenilirliği (CR) ve hesaplanan ortalama varyans (AVE) kullanılmıştır. Kompozit güvenilirlik (composite reliability) analizinde tüm yapıların 0.70 değerinin üzerinde olduğu görülmektedir. Bu değer sınır değer olarak kabul edilen 0.70 değerinden büyük olduğundan içsel tutarlılığın bulunduğu sonucuna ulaşılabilir (Nunnally, 1978). Tüm yapılar için hesaplanan ortalama varyans (AVE) değerleri 0,538 ile 0,604 değerleri

arasında değişmektedir. AVE değerlerinin bu değerler arasında çıkması tüm yapıların birbirlerinden ayrıştığını ifade etmektedir (Fornell and Larcker, 1981). Nunnally (1978), cronbach katsayısının 0.70`den büyük olmasının gerektiğinin önemine vurgu yapmıştır. Tablo 2 de görüleceği üzere tüm değişkenler 0,70 değerinin üzerindedir. 
Tablo 2: Bileşik Güvenilirlik ve Geçerlilik Tablosu

\begin{tabular}{|lcccc|}
\hline & Cronbach's Alpha ( $\boldsymbol{\alpha})$ & Composite Reliability (CR) & \multicolumn{2}{c|}{ Average Variance Extracted (AVE) } \\
EKiDS & 0,931 & 0,94 & 0,550 & 0,538 \\
KÇY & 0,905 & 0,921 & & 0,604 \\
KiKSBTK & 0,868 & 0,901 & 0,585 \\
KiKSE & 0,763 & 0,849 & 0,556 \\
KiKSÜYD & 0,899 & 0,918 & \\
\hline
\end{tabular}

\subsection{Faktör Analizi}

Doğrulayıcı faktör analizi uygulanırken faktörlerin minimum 0,50 değerinde olması önerilmiştir (Hulland, 1999). Analiz sonuçlarına göre faktör yükleri, 0.5 'ten daha büyük göstermektedir.

\section{Tablo 3: Faktör Yükleri Tablosu}

\begin{tabular}{|c|c|c|c|c|}
\hline & Yol & Yol Katsayısı & P Değeri & Geçerlilik \\
\hline Hipotez 1 & KIKSÜYD > > >> KIKSEE & $\beta=0,45$ & 0,000 & Desteklenmiştir \\
\hline Hipotez 2 & 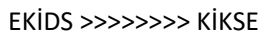 & $\beta=0,206$ & 0,001 & Desteklenmiştir \\
\hline Hipotez 3 & 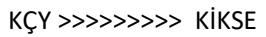 & $\beta=0,109$ & 0,026 & Desteklenmiştir \\
\hline Hipotez 4 & 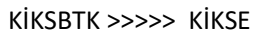 & $\beta=0,2$ & 0,008 & Desteklenmiştir \\
\hline
\end{tabular}

\subsection{Yapısal Eşitlik Analiz Sonucu}

Yapısal eşitlik (SEM) sonuçlarına göre bağımlı ve bağımsız etkenler arasındaki ilişki aşağıdaki tabloda gösterilmiştir.

Tablo 4: Yol Katsayıları Tablosu

\begin{tabular}{|c|c|c|c|c|c|}
\hline & EKIDS & KÇY & кіKSBTK & KIKSE & KIKKSÜYD \\
\hline EKIDS1 & 0,71 & 0,119 & 0,295 & 0,396 & 0,351 \\
\hline EKIDS10 & 0,749 & 0,195 & 0,34 & 0,378 & 0,378 \\
\hline EKIDS11 & 0,791 & 0,312 & 0,346 & 0,418 & 0,393 \\
\hline EKIDS13 & 0,738 & 0,279 & 0,328 & 0,416 & 0,372 \\
\hline EKIDS14 & 0,641 & 0,298 & 0,486 & 0,456 & 0,543 \\
\hline EKIDS2 & 0,77 & 0,182 & 0,318 & 0,49 & 0,462 \\
\hline EKIDS3 & 0,748 & 0,185 & 0,335 & 0,481 & 0,423 \\
\hline EKIDS4 & 0,638 & 0,063 & 0,392 & 0,433 & 0,426 \\
\hline EKIDS5 & 0,8 & 0,163 & 0,427 & 0,543 & 0,453 \\
\hline EKIDS6 & 0,715 & 0,244 & 0,304 & 0,433 & 0,388 \\
\hline EKIDS7 & 0,769 & 0,308 & 0,314 & 0,392 & 0,384 \\
\hline EKIDS8 & 0,757 & 0,275 & 0,399 & 0,428 & 0,451 \\
\hline EKIDS9 & 0,789 & 0,273 & 0,34 & 0,302 & 0,338 \\
\hline KÇY1 & 0,231 & 0,644 & 0,171 & 0,246 & 0,135 \\
\hline KÇY10 & 0,228 & 0,725 & 0,247 & 0,295 & 0,240 \\
\hline KÇY2 & 0,18 & 0,677 & 0,212 & 0,318 & 0,239 \\
\hline KÇY3 & 0,134 & 0,738 & 0,327 & 0,319 & 0,267 \\
\hline KÇY4 & 0,317 & 0,786 & 0,277 & 0,269 & 0,242 \\
\hline KÇY5 & 0,218 & 0,748 & 0,147 & 0,145 & 0,150 \\
\hline KÇY6 & 0,241 & 0,756 & 0,221 & 0,287 & 0,243 \\
\hline KÇY7 & 0,184 & 0,666 & 0,165 & 0,199 & 0,199 \\
\hline KÇY8 & 0,155 & 0,769 & 0,217 & 0,209 & 0,156 \\
\hline KÇY9 & 0,279 & 0,807 & 0,241 & 0,316 & 0,298 \\
\hline KIKSBTK1 & 0,388 & 0,242 & 0,799 & 0,468 & 0,521 \\
\hline KIKSBTK2 & 0,292 & 0,263 & 0,803 & 0,427 & 0,518 \\
\hline KIKSBTK4 & 0,4 & 0,206 & 0,79 & 0,568 & 0,650 \\
\hline KIKSBTK5 & 0,535 & 0,35 & 0,829 & 0,635 & 0,698 \\
\hline KIKSBTK6 & 0,256 & 0,137 & 0,671 & 0,458 & 0,513 \\
\hline
\end{tabular}




\begin{tabular}{|c|c|c|c|c|c|}
\hline KIKSBTK7 & 0,326 & 0,242 & 0,758 & 0,508 & 0,530 \\
\hline KIKSE2 & 0,442 & 0,298 & 0,439 & 0,729 & 0,480 \\
\hline KIKSE5 & 0,41 & 0,241 & 0,643 & 0,808 & 0,671 \\
\hline KIKSE8 & 0,478 & 0,287 & 0,45 & 0,739 & 0,538 \\
\hline KIKSE9 & 0,48 & 0,319 & 0,495 & 0,78 & 0,582 \\
\hline KIKSÜYD2 & 0,464 & 0,254 & 0,629 & 0,654 & 0,850 \\
\hline KIKSÜYD3 & 0,398 & 0,288 & 0,608 & 0,58 & 0,804 \\
\hline KIKSÜYD4 & 0,525 & 0,244 & 0,62 & 0,643 & 0,786 \\
\hline KIKSÜYD5 & 0,539 & 0,249 & 0,566 & 0,607 & 0,834 \\
\hline KIKSÜYD6 & 0,407 & 0,239 & 0,462 & 0,55 & 0,667 \\
\hline KIKSÜYD7 & 0,371 & 0,175 & 0,4 & 0,521 & 0,655 \\
\hline KIKSÜYD8 & 0,379 & 0,216 & 0,646 & 0,483 & 0,740 \\
\hline KIKSÜYD9 & 0,321 & 0,176 & 0,539 & 0,535 & 0,709 \\
\hline KIKSÜYD1 & 0,335 & 0,221 & 0,553 & 0,375 & 0,632 \\
\hline
\end{tabular}

Tablo 4 de kamu iç kontrol sistemi etkinliği ile kamu iç kontrol sistemine üst yönetim desteği, etkin kamu iç denetim sistemi, kamu çalışanları yetkinliği ve kamu iç kontrol sisteminde bilgi teknolojileri kullanımı arasında pozitif yönlü bir ilişki vardır.

\section{SONUÇ}

Avrupa Birliği ülkelerinin kamu sektöründe etkin olarak uygulanan Coso modeli esaslı iç kontrol sistemi, Avrupa Birliğine aday ülkeler için de gerekli görülmekte bu ülkelerin kamu yönetim sistemlerinde uygulanması önerilmektedir. Bu kapsamda Avrupa Birliği adayı Türkiye'de 5018 sayılı kanun ile kamu iç kontrol sistemi uygulamaya konulmuş olmasına rağmen kamu iç kontrol sistemi etkinliği istenilen seviyeye ulaşamamış, Avrupa Birliği üyelik sürecinde "Mali Kontrol” başlıklı 32. Faslın kapatılamamıştır. Bu nedenle kamu iç kontrol sistemini etkinleştiren faktörlerin ortaya çıkarılması gerekmektedir. Bu amaç doğrultusunda, Türkiye'deki devlet üniversitelerinde görev yapan 176 kişiye uygulanan anket çalışmasında elde edilen veriler Smart PLS 3.0 programıyla analiz edilmiştir. Elde edilen sonuçlara göre kamu iç kontrol sistemine üst yönetim desteği, etkin kamu iç denetim sistemi, kamu çalışanları yetkinliği ve kamu iç kontrol sisteminde bilgi teknolojileri kullanımının kamu iç kontrol sistemi etkinliğini pozitif ve anlamlı etkilediği sonucuna varılmıştır. Bundan sonraki araştırmalarda, bu faktörlerin kamu iç kontrol sistemi etkinliğine etkisi 5018 Sayılı Kanununa dahil diğer kurumlar üzerinden analiz edilebilir ve kamu iç kontrol sistemi etkinliğine etki eden faktörler başlığında özetlenen diğer faktörler araştırmalara dahil edilebilir.

\section{REFERANSLAR}

Akyel R., (2010), "Yönetimde İç Kontrol, İç Denetim ve Dış Denetim Fonksiyonlarının Birbirleri İle İlişkileri ve Türk Kamu Yönetiminde Uygulamalarının Değerlendirilmesi", Çukurova Üniversitesi Sosyal Bilimler Enstitüsü, (3), 1-22.

Alzeban, A., \& Gwilliam, D., (2014), "Factors Affecting the Internal Audit Effectiveness: A Survey of the Saudi Public Sector." Journal of International Accounting, Auditing and Taxation, 23(2), 74-86.

Aunga D.A.O. and Ilomo O., (2017), “Comparative Study on the Usage of Information Technology On Internal Control Systems In Private and Public Secondary Schools in Arumeru District.", The International Journal of Social Sciences and Humanities Invention, 4(1): 3231-3238.

Aziz M.A.A., Said J. \& Alam M.M., (2015), "Assessment of the Practices of Internal Control System in the Public Sectors of Malaysia.", Asia-Pacific Management Accounting Journal, 10 (1), 43-62.

Cohen, A. \& Sayag, G., (2010). "The Effectiveness of internal auditing: An empirical examination of its determinants in Israeli organizations", Australian Accounting Review, 54 (20), 296-307.

Dormán Z. I., Görgényi G. \& Horváth M., (2013), "Evaluation of the Internal Control System at Central Budgetary Institutions”, Public Finance Quarterly, Vol:58 Issue:2, p:199-218.

Fornell, C. \& Larcker, D.F. (1981). "Evaluating structural models with unobservables variables and measurement error", Journal of Marketing Research, 28, 39-50.

Giriūnas L., (2009), "Evaluation of Condition Of Internal Control System In The Company”, Ekonomika Ir Vadyba: Aktualijos Ir Perspektyvos, Vol. 1, No. 14, pp. 103-113.

Hulland, J., (1999). "Use of partial least squares (PLS) in strategic management research: A review of four recent studies", Strategic Management Journal, 20 (2), 195-204.

Korkmaz U., (2007), "Kamuda İç Denetim (1)”, Bütçe Dünyası, Ankara (25), 4-15. 
Kumuthinidevi S., (2016), "Study on Effectiveness of the Internal Control System in the Private Banks of Trincomalee", International Journal of Scientific and Research Publications, Volume 6, Issue 6, 600-612.

Nunnally J., (1978), "Psychometric Theory", McGraw-Hill, New York, NY.

Jokipii A., (2010), "Determinants and Consequences of Internal Control in Firms: a Contingency Theory Based Analysis", Journal of Management Governance, 14, pp. 115-144.

Lalic S, Jovanovic D., Nikolic M., \& Vulovic V., (2011), “Internal Control and Problems of Modern Management In The International Environment.", Research Journal of Agricultural Science, 43 (3), 406-415.

Root S. J., (1998), “Beyond COSO:Internal Control to Enhance Corporate Governance”, John Wiley\&Sons Inc., New York.

Schwarzer R. and Jerusalem M., (1995), Generalized Self-Efficacy Scale. In J. Weinman, S. Wright, and M. Johnston, Measures in Health Psychology: A User's Portfolio. Causal and Control Beliefs, (pp. 35-37). Windsor, UK: NFER-NELSON

Verovska L., (2012), "Internal Control System as Continuous Basis of Efficient and Stable Company Development", Regional Formation and Development Studies, No:3 (8), 240-246.

Vijayakumar A. N. \& Nagaraja N., (2012), “Internal Control Systems: Effectiveness of Internal Audit in Risk Management at Public Sector Enterprises.", Bvımr Management Edge, 5(1), 1-8.

Yılancı M., (2006), “iç̧ Denetim, Türkiye'nin 500 Büyük Sanayi İşletmesi Üzerine Bir Araştırma”, Nobel Yayınları. 